\title{
Impact of night-time symptoms in COPD: a real-world study in five European countries
}

This article was published in the following Dove Press journal:

International Journal of COPD

26 November 2013

Number of times this article has been viewed

\author{
David Price \\ Mark Small ${ }^{2}$ \\ Gary Milligan² \\ Victoria Higgins ${ }^{2}$ \\ Esther Garcia Gil ${ }^{3}$ \\ Jordi Estruch ${ }^{3}$ \\ 'Centre of Academic Primary Care, \\ University of Aberdeen, Aberdeen, \\ UK; ${ }^{2}$ Adelphi Real World, Adelphi \\ Mill, Bollington, UK; ${ }^{3}$ Almirall S.A., \\ Barcelona, Spain
}

Correspondence: David Price Centre of Academic Primary Care, University of Aberdeen,

Polwarth Building, Foresterhill, Aberdeen AB25 2ZD, UK

Tel +442081233923

Fax +448082800792

Email david@rirl.org
Background: Sleep quality is often poor in patients with chronic obstructive pulmonary disease (COPD). A cross-sectional European survey investigated the prevalence of night-time symptoms in COPD to evaluate the level of disconnect between physician and patient perceptions of the presence of night-time symptoms, and to compare the characteristics of patients with and without night-time symptoms.

Methods: A total of 251 primary care physicians and 251 respiratory specialists completed record forms on 2,807 patients with COPD. The forms captured information on patient demographics, lung function, COPD severity, and symptoms. Patients completed questionnaires on the time of day when their COPD symptoms bothered them, and the impact of COPD on their ability to get up in the morning and on sleep. Data were compared between groups (those with and without night-time symptoms) using $t$-tests or Wilcoxon signed rank tests. The kappa statistic was used to assess the level of disconnect between physician and patient perceptions of the impact of night-time symptoms.

Results: Most patients (78\%) reported night-time disturbance. Patients with night-time symptoms experienced more daytime breathlessness (mean modified Medical Research Council dyspnea scale score 2.4 versus 1.1 ) and exacerbations in the previous 12 months (mean 1.7 versus 0.4 ), and received more maintenance therapy (mean of 2.8 versus 2.3 products) than those without. Concordance between the frequency of physician-reported ( $67.9 \%$ of patients) and patient-reported (68.5\% of patients) night-time symptoms was good. Physicians significantly underestimated the impact of COPD on the patient's ability to get up in the morning and on sleep (fair-moderate agreement). Physician-reported night-time symptoms were present for $41.2 \%$ of patients who could be categorized by Global initiative for chronic Obstructive Lung Disease (GOLD) group ( $\mathrm{n}=937$ ), increasing from $20.9 \%$ of those in the low-risk group to $77.4 \%$ of those in the high-riskgroup.

Conclusion: Patients with COPD experience night-time symptoms regardless of GOLD group, that impact on their ability to get up in the morning and on their sleep quality.

Keywords: chronic obstructive pulmonary disease, night-time symptoms, sleep quality, burden

\section{Introduction}

Chronic obstructive pulmonary disease (COPD) is a progressive respiratory condition characterized by chronic airflow obstruction that is not fully reversible. ${ }^{1}$ Sleep quality is often poor in patients with COPD, and patients frequently report difficulty in falling asleep, nocturnal awakening, and insomnia. ${ }^{2,3}$ Epidemiological data suggest that as many as $76 \%$ of patients may experience frequent nocturnal awakening. ${ }^{2,4}$ Compared with individuals without COPD matched for age, sex, and body mass 
index, patients with stable mild to moderate COPD appear to be more likely to report insomnia as well as difficulty in initiating and maintaining sleep. ${ }^{2}$ Poor sleep quality has been associated with a reduced quality of life in patients with COPD. ${ }^{5,6}$

Despite the apparent prevalence of poor sleep quality and sleep disturbance in patients with COPD, the contribution of COPD-related night-time symptoms has not been widely evaluated. Indeed, there is no formal definition of night-time symptoms in COPD. ${ }^{4}$

The potential long-term adverse consequences of sleep deprivation on human health are well documented and may include an increased risk of cardiovascular disease and all-cause mortality as well as depression. ${ }^{7-9}$ As such, nighttime symptoms and the associated sleep disturbance and deprivation have the potential to impact a range of long-term outcomes for patients with COPD. ${ }^{4-6}$

Understanding the impact of COPD symptoms on sleep quality and disturbance should enhance the ability of physicians to manage and relieve the symptoms of the disease and potentially improve long-term outcomes for patients with COPD. The objectives of the current analysis were to evaluate the incidence of COPD-related night-time symptoms as reported by physicians and patients with COPD, and to test the hypothesis that the prevalence and impact of COPD-related night-time symptoms increase with increasing COPD severity. The analysis also sought to evaluate the level of disconnect between physician and patient perceptions of the presence of night-time symptoms, and to compare the characteristics of patients, including their Global initiative for chronic Obstructive Lung Disease (GOLD) grouping, with and without physician-reported night-time symptoms in order to explore the additional burden of night-time symptoms in patients with COPD.

\section{Materials and methods}

Data were drawn from the Adelphi Respiratory Disease Specific Programme, ${ }^{10}$ a real-life, patient record-based survey of respiratory specialists and primary care physicians in France, Germany, Italy, Spain, and the UK conducted between June and September 2009.

The Respiratory Disease Specific Programme survey adhered to version 6.3 of the European Pharmaceutical Market Research Association (EphMRA) code of conduct governing market research, including the guidance related to collecting written informed consent from all participating patients and the anonymous and aggregated reporting of data. ${ }^{11}$ To ensure compliance with data protection laws, all data were deidentified and aggregated prior to receipt by Adelphi Real World.

\section{Data collection}

Physicians eligible to participate included respiratory specialists and primary care physicians caring for patients with COPD who were personally responsible for decisions about their treatment. In addition, physicians were required to see at least three patients with COPD each week.

Eligible physicians provided information on six consecutive patients with COPD (aged $>40$ years with a history of smoking and a diagnosis of airflow obstruction). Information was collected via a physician record form. Physician-reported data included patient demographics, most recent forced respiratory volume over one second $\left(\mathrm{FEV}_{1}\right)$, physician subjective severity assessment of COPD, exacerbation frequency in the last 12 months, and the modified Medical Research Council (mMRC) dyspnea scale score. ${ }^{1}$ Additional information included the time of day the patient is most commonly bothered by their COPD overall (daytime only, night-time only, primarily daytime with occasional night-time, primarily night-time with occasional daytime, or both day and night), the time of day of individual COPD symptoms (daytime, night-time, and/or getting up in the morning), the impact of night-time symptoms on sleep (evaluated using a sevenpoint Likert scale [1=no impact, $7=$ constant impact $]$ ), and the frequency of nocturnal awakening due to COPD symptoms (not at all, once or twice a week, once a week, 2-3 nights a week, or $\geq 4$ nights a week).

Patients for whom a physician record form had been completed were then invited to voluntarily complete a selfreport questionnaire. Patient-reported data included the time of day the patient is bothered by their COPD (daytime only, night-time only, primarily daytime with occasional nighttime, primarily night-time with occasional daytime, or both day and night), the impact of COPD on the patient's ability to get up in the morning and on sleep using a seven-point Likert scale ( $1=$ no impact, $7=$ constant impact), the Jenkins Sleep Questionnaire, ${ }^{12}$ the frequency of nocturnal awakening in the last 4 weeks due to COPD symptoms (not at all, once or twice a week, once a week, 2-3 nights a week, or $\geq 4$ nights a week), the mMRC, and health-related quality of life using the EuroQol 5 dimensions measure (EQ-5D). ${ }^{13}$ Patients completed the self-report questionnaire independently and returned it to their physician in a sealed envelope, which was then returned unopened to the study coordinator. All responses were voluntary and anonymous to preserve patient confidentiality. Elements of the questionnaire that 
did not form part of the validated tools were developed in English and then translated into the relevant language by native speakers. Subsequently, an independent UK translation agency performed a validation before approval.

\section{Statistical analyses}

Demographic and disease characteristics were compared between groups (those with and without physician-reported night-time symptoms) using $t$-tests or Wilcoxon signed rank tests. The kappa statistic level of agreement was used to assess the level of disconnect between physician and patient perceptions of the impact of night-time symptoms according to Landis and Koch, as follows: ${ }^{14}<0.00$ poor; 0.00-0.20 slight; 0.21-0.40 fair; $0.41-0.60$ moderate; $0.61-0.80$ substantial; 0.81-1.00 almost perfect.

Cohorts were selected on the basis of availability of responses to particular questions. Where a response was not available, the patient was excluded from that particular analysis.

Double-robust estimates ${ }^{15,16}$ of the effect of night-time disturbances on a variety of health-related and resource userelated factors were computed. This method enables efficient adjustment for potential confounding factors. The confounding factors used here were drawn from the physician report form and included age, sex, body mass index (calculated from height and weight), smoking status (current or ex-smoker), physician subjective assessment of COPD severity, presence of depression or anxiety, and physician-reported medication compliance (frequency per day). Compliance was defined as the extent to which patients, as assessed by their physician, followed their prescribing instructions and advice with regard to dosing frequency and inhaler device usage on a five-point Likert scale from "not at all compliant" to "fully compliant". The method involves generating a propensity score based on the confounding factors (predicted values from a logistic regression for night-time disturbances). The inverse of this propensity score is then used in appropriate regressions on a given outcome, which also includes the confounding factors as covariates. The double-robust estimate is calculated from the results of these regressions, and shows how each outcome differs between patients with night-time disturbances and those with no night-time disturbance, having adjusted for confounding factors.

As per the GOLD 2013 strategy document, patients for whom an mMRC score (patient-reported) and either an $\mathrm{FEV}_{1}$ score or exacerbation history (physician-reported), or both, were available were stratified by GOLD groups A-D. ${ }^{1}$ A valid $\mathrm{FEV}_{1}$ measurement was available for almost $50 \%$ of patients permitting full GOLD grouping; for the remaining patients GOLD grouping was by exacerbations only. The proportion of patients with and without night-time symptoms in each GOLD category was determined.

\section{Results}

A total of 251 primary care physicians and 251 respiratory specialists provided information on 2,807 patients. Table 1 provides an overview of the demographics and disease characteristics of the patient population. The cohort of patients for whom physician-only data were available tended to be slightly older, had a slightly lower mean $\mathrm{FEV}_{1}$, and were slightly more breathless (all as reported by their physician) than the cohort of patients with both physicianreported and patient-reported data (Table 1). Data were available to categorize 1,699 patients by GOLD group (a patient-reported mMRC score and either an $\mathrm{FEV}_{1}$ score or physician-reported exacerbation history). The majority of patients $(66.3 \%)$ were classified as GOLD group A or B (low-risk).

\section{Incidence of night-time symptoms}

Night-time sleep disturbance was reported by $78 \%$ of patients (Jenkins Sleep Questionnaire score $>1$ reported in the last 28 days). Figure 1 illustrates the proportion of patients reporting various types of sleep disturbance in the previous 28 days.

\section{Awareness of night-time symptoms by physicians}

Agreement between physician-reporting and patientreporting of night-time symptoms was evaluated in the subset of patients who completed a self-report questionnaire $(n=1,777)$. In this subgroup, a similar proportion of patients reported the presence of night-time symptoms whether based on physician's opinion $(67.9 \%)$ or patient's opinion $(68.5 \%)$.

Figure 2 shows the time of day that COPD symptoms bothered patients, as reported by both the physicians and patients. There were no statistically significant differences between physician and patient reporting of the time of day COPD symptoms bothered patients.

\section{Night-time symptoms and COPD disease severity}

Physicians reported the presence of night-time symptoms in 1,207/1,777 (67.9\%) patients for whom both physicianreported and patient-reported data were available. Patients with night-time symptoms (as reported by their physician) 
Table I Demographic and disease characteristics

\begin{tabular}{|c|c|c|c|c|c|c|c|}
\hline Characteristic & $\begin{array}{l}\text { All } \\
\text { patients }\end{array}$ & $\mathbf{n}$ & $\begin{array}{l}\text { Patients with physician- } \\
\text { reported and patient- } \\
\text { reported data }\end{array}$ & $\mathbf{n}$ & $\begin{array}{l}\text { Patients with } \\
\text { physician-reported } \\
\text { data onlyg }\end{array}$ & $\mathbf{n}$ & $P$-value \\
\hline Mean age, years (SD) & $65.7(10.5)$ & 2,807 & $65.0(10.5)$ & $\mathrm{I}, 885$ & $67.0(10.3)$ & 922 & $<0.000 \mathrm{I}^{\mathrm{a}}$ \\
\hline Sex, $\%$ male & 69.9 & 2,792 & 71.6 & $\mathrm{I}, 875$ & 66.4 & 917 & $0.0057^{b}$ \\
\hline Mean BMI, kg/m² (SD) & $26.3(7.6)$ & 2,690 & $26.7(8.5)$ & $\mathrm{I}, 825$ & $25.6(5.1)$ & 865 & $0.0002^{\mathrm{a}}$ \\
\hline Ethnic origin, $n(\%)$ & & 2,785 & & $\mathrm{I}, 866$ & & 919 & $0.0003^{c}$ \\
\hline White/Caucasian & $2,662(95.6)$ & & I,79I (96.0) & & 87I (94.8) & & \\
\hline Afro-Caribbean & $28(1.0)$ & & $13(0.7)$ & & $15(1.6)$ & & \\
\hline Asian (Indian subcontinent) & $8(0.3)$ & & $2(0.1)$ & & $6(0.7)$ & & \\
\hline Asian (other) & $17(0.6)$ & & $8(0.4)$ & & $9(1.0)$ & & \\
\hline Hispanic & $58(2.1)$ & & $47(2.5)$ & & $11(1.2)$ & & \\
\hline Other & $12(0.4)$ & & $5(0.3)$ & & $7(0.8)$ & & \\
\hline Smoking status, n (\%) & & 2,654 & & 1,755 & & 899 & $0.899 /^{b}$ \\
\hline Ex-smoker & $\mathrm{I}, 648(62.1)$ & & $\mathrm{I}, 088(62.0)$ & & $560(62.3)$ & & \\
\hline Current smoker & $\mathrm{I}, 006(37.9)$ & & $667(38.0)$ & & $339(37.7)$ & & \\
\hline Mean FEV $(\%$ predicted) & $58.4(20.2)$ & $|, 43|$ & $60.3(20.1)$ & 915 & $54.9(19.9)$ & 516 & $<0.000 I^{\mathrm{a}}$ \\
\hline GOLD group, n (\%) & & 1,699 & & 1,699 & & 0 & \\
\hline A & $7 \mid 2(4 \mid .9)$ & & $7 \mid 2(4 \mid .9)$ & & & & \\
\hline B & $4 \mid 4(24.4)$ & & $4 \mid 4(24.4)$ & & & & \\
\hline C & $191(11.2)$ & & $191(11.2)$ & & & & \\
\hline $\mathrm{D}$ & $382(22.5)$ & & $382(22.5)$ & & & & \\
\hline Mean mMRC score (SD) & $1.68(1.3)$ & 2,774 & $1.58(1.2)$ & 1,859 & $\mathrm{I} .87(\mathrm{I} .3)$ & 915 & $<0.000 \mathrm{I}^{\mathrm{a}}$ \\
\hline mMRC level of breathlessness, $n(\%)$ & & 2,774 & & 1,859 & & 915 & $<0.000 \mathrm{I}^{\mathrm{d}}$ \\
\hline Too breathless to leave the house & $258(9.3)$ & & $151(8.1)$ & & $107(11.7)$ & & \\
\hline $\begin{array}{l}\text { Stops for a breath after walking } \\
\text { a few minutes, even on level ground }\end{array}$ & $540(19.5)$ & & $344(18.5)$ & & $196(21.4)$ & & \\
\hline $\begin{array}{l}\text { Walks slower than most people } \\
\text { of the same age }\end{array}$ & $603(21.7)$ & & $372(20.0)$ & & $231(25.3)$ & & \\
\hline $\begin{array}{l}\text { Gets breathless when hurrying } \\
\text { on level ground or walking } \\
\text { up a slight incline }\end{array}$ & $796(28.7)$ & & $566(30.5)$ & & $230(25.1)$ & & \\
\hline $\begin{array}{l}\text { Only gets breathless after } \\
\text { exercising heavily }\end{array}$ & $577(20.8)$ & & $426(22.9)$ & & $15 \mid(16.5)$ & & \\
\hline $\begin{array}{l}\text { Mean Jenkins Sleep Questionnaire } \\
\text { score (SD) }\end{array}$ & $4.73(4.6)$ & $\mathrm{I}, 746$ & $4.73(4.6)$ & $\mathrm{I}, 746$ & - & 0 & $-^{\mathrm{a}}$ \\
\hline Concomitant conditions, ${ }^{\mathrm{e}} \mathrm{n}(\%)$ & & 2,807 & & $\mathrm{I}, 885$ & & 922 & \\
\hline Elevated cholesterol & $606(21.6)$ & & $424(22.5)$ & & $|8|(19.6)$ & & $0.0950^{c}$ \\
\hline Hypertension & $\mathrm{I}, 207(43.0)$ & & $837(44.4)$ & & $372(40.3)$ & & $0.0540^{c}$ \\
\hline Diabetes & $340(12.1)$ & & $226(12.0)$ & & $114(12.4)$ & & $0.8060^{c}$ \\
\hline Prostate disorder & $320(11.4)$ & & $230(12.2)$ & & $90(9.8)$ & & $0.0580^{c}$ \\
\hline Anxiety & $280(10.0)$ & & $179(9.5)$ & & $101(11.0)$ & & $0.2280^{b}$ \\
\hline Depression & $361(12.9)$ & & $222(11.8)$ & & $139(15.1)$ & & $0.0163^{b}$ \\
\hline Time of day of symptoms, n (\%) & & 2,754 & & $\mathrm{I}, 848$ & & 906 & $0.0130^{c}$ \\
\hline Daytime only & $90 \mathrm{I}(32.7)$ & & $587(3 \mid .8)$ & & 314 (34.7) & & \\
\hline $\begin{array}{l}\text { Primarily daytime with } \\
\text { occasional night time }\end{array}$ & $I, 02 I(37 . I)$ & & $704(38.1)$ & & $317(35.0)$ & & \\
\hline Both day and night & $670(24.3)$ & & $432(23.4)$ & & $238(26.3)$ & & \\
\hline $\begin{array}{l}\text { Primarily night time with } \\
\text { occasional daytime }\end{array}$ & $115(4.2)$ & & $89(4.8)$ & & $26(2.9)$ & & \\
\hline Night time only & 47 (I.7) & & $36(2.0)$ & & II (I.2) & & \\
\hline Respiratory drug therapy, n (\%) & & 2,807 & & $\mathrm{I}, 885$ & & 922 & $<0.0001^{c}$ \\
\hline SABA only & $200(7.1)$ & & $133(7.1)$ & & $67(7.3)$ & & \\
\hline LABA & $99(3.5)$ & & $81(4.3)$ & & $18(2.0)$ & & \\
\hline LAMA & $540(19.2)$ & & $390(20.7)$ & & $150(16.3)$ & & \\
\hline ICS & $87(3.1)$ & & $60(3.2)$ & & $27(2.9)$ & & \\
\hline ICS/LABA & $701(25.0)$ & & $488(25.9)$ & & $213(23.1)$ & & \\
\hline ICS/LAMA & $45(1.6)$ & & $28(1.5)$ & & $17(\mathrm{I} .8)$ & & \\
\hline
\end{tabular}

(Continued) 
Table I (Continued)

\begin{tabular}{lllll}
\hline Characteristic & $\begin{array}{l}\text { All } \\
\text { patients }\end{array}$ & $\mathbf{n}$ & $\begin{array}{l}\text { Patients with physician- } \\
\text { reported and patient- } \\
\text { reported data }\end{array}$ & $\begin{array}{l}\text { n } \\
\text { physician-reported } \\
\text { data onlyg }^{\mathbf{g}}\end{array}$ \\
\hline LABA/LAMA & $104(3.7)$ & $83(4.4)$ & $\mathbf{n}$-value \\
ICS/LABA/LAMA & $911(32.5)$ & $544(28.9)$ & $367(39.8)$ \\
Other & $120(4.3)$ & $78(4.1)$ & $42(4.6)$ \\
\hline
\end{tabular}

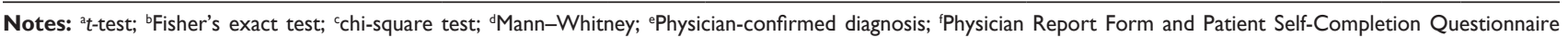
available; 'PPysician Report Form only available.

Abbreviations: BMI, body mass index; FEV , forced respiratory volume over one second; GOLD, Global initiative for chronic Obstructive Disease; ICS, inhaled corticosteroid; LABA, long-acting bronchodilator; LAMA, long-acting antimuscarinic agent; mMRC, modified Medical Research Council; SABA, short-acting bronchodilator; SD, standard deviation.

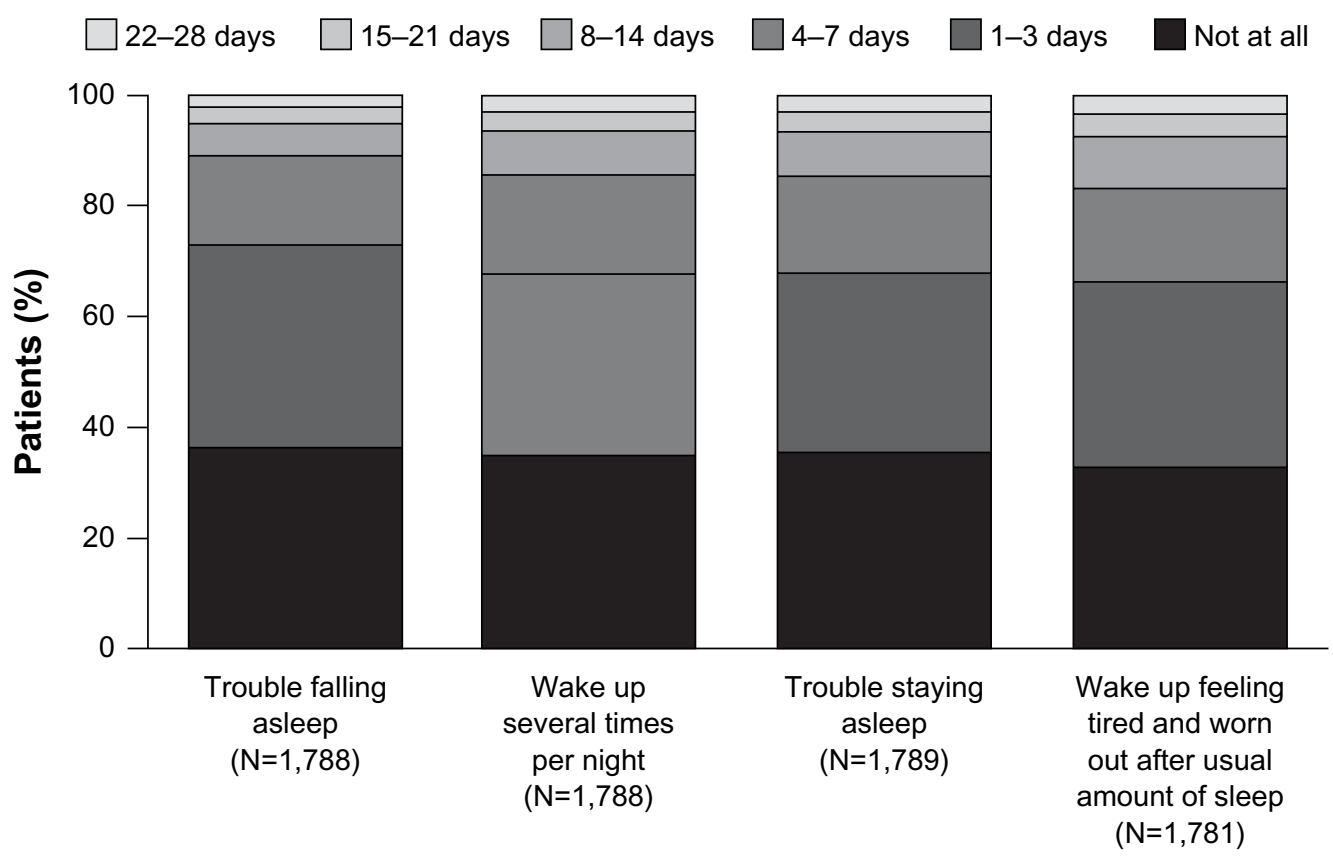

\section{Sleep disturbance}

Figure I Proportion of patients reporting the four types of sleep disturbance in the previous 28 days as defined by the Jenkins Sleep Questionnaire.

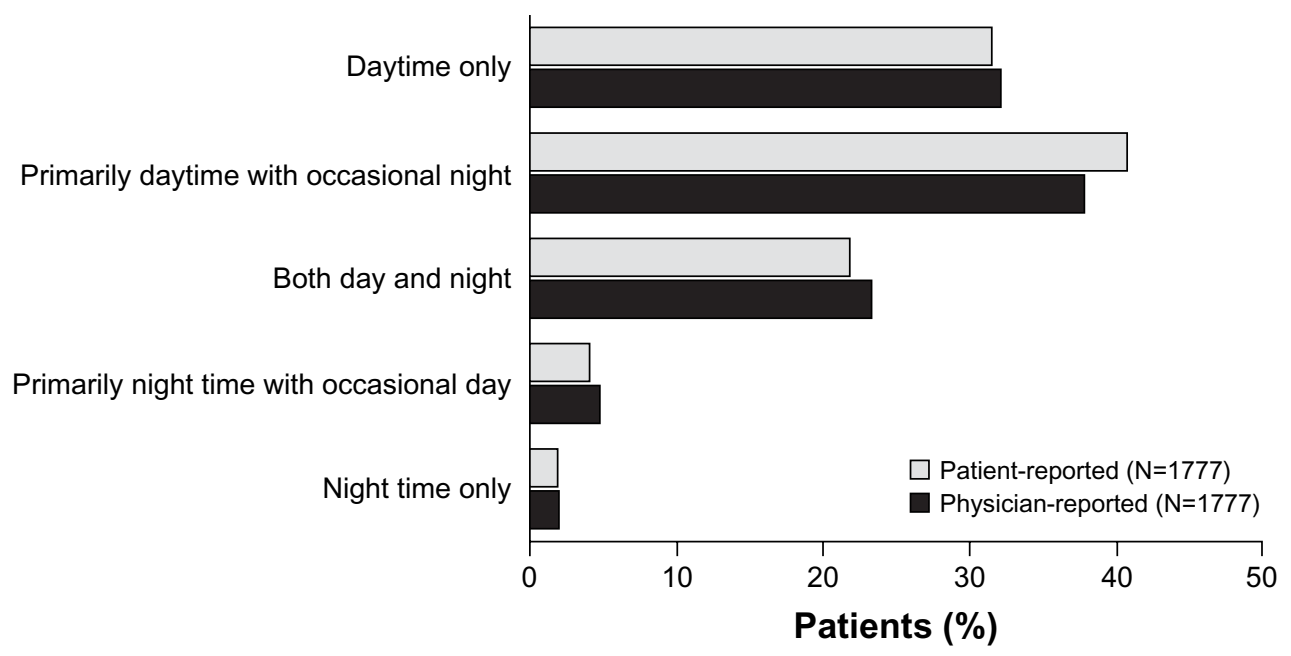

Figure 2 Time of day that the patient's COPD symptoms bother them, as reported by physicians and the patients themselves (the analysis set was the cohort for whom both physician-reported and patient-reported data were available).

Abbreviation: COPD, chronic obstructive pulmonary disease. 
experienced more daytime breathlessness and exacerbations in the previous 12 months (both physician-reported), and received more maintenance therapy (physician-reported) compared with patients classified as having daytime only symptoms (Table 2).

Information was available to categorize a total of 1,699 patients by GOLD group; of these, data on the presence or absence of night-time symptoms were available for 937 (for the remaining patients physician-reported information on the presence of night-time symptoms were not available).
Physicians reported the presence of night-time symptoms in $386 / 937$ patients $(41.2 \%), 192$ of whom (50\%) were assigned to the low-risk groups (A and B) and 194 (50\%) were assigned to one of the two high-risk groups (C and D).

\section{Association between night-time symptoms and sleep and health status in patients with COPD}

Patients whose physician reported that they experienced night-time symptoms were significantly more likely to

Table 2 Characteristics of patients with and without physician-reported night time symptoms

\begin{tabular}{|c|c|c|c|}
\hline Characteristic & With NTS & Without NTS ${ }^{f}$ & $P$-value \\
\hline \multirow[t]{2}{*}{ Mean age, years } & 67.6 & 64.3 & \\
\hline & $n=670^{g}$ & $n=901$ & \\
\hline Sex, n (\%) male & $462(69.2)$ & $621(69.2)$ & 1.0 \\
\hline \multicolumn{3}{|l|}{ Smoking status, $\mathrm{n}(\%)^{\mathrm{a}}$} & 0.456 \\
\hline Ex-smoker & $40 I(6 I .7)$ & $509(59.7)$ & \\
\hline Current smoker & $249(38.3)$ & $344(40.3)$ & \\
\hline \multirow{2}{*}{ Mean FEV,$\%$ predicted } & 49.4 & 64.1 & $<0.0001$ \\
\hline & $n=320$ & $n=499$ & \\
\hline \multicolumn{3}{|l|}{ GOLD group, $\mathrm{n}(\%)^{\mathrm{c}}$} & $<0.000$ I \\
\hline A & $92(20.9)$ & $347(79.0)$ & \\
\hline B & $100(45.9)$ & II 8 (54.I) & \\
\hline $\mathrm{C}$ & $43(50.6)$ & $42(49.4)$ & \\
\hline $\mathrm{D}$ & I5I (77.4) & $44(22.6)$ & \\
\hline \multirow[t]{2}{*}{ Mean mMRC score (SD) ${ }^{b}$} & 2.4 & I.I & $<0.000$ I \\
\hline & $n=662$ & $n=891$ & \\
\hline Level of breathlessness (mMRC), $n(\%)^{d}$ & $\mathrm{n}=662$ & $n=891$ & $<0.0001$ \\
\hline Too breathless to leave the house & $147(22.2)$ & $15(1.7)$ & \\
\hline Stops for a breath after walking a few minutes & $189(28.5)$ & $87(9.8)$ & \\
\hline Walks slower than most people of the same age & $150(22.7)$ & $183(20.5)$ & \\
\hline Gets breathless when hurrying on level ground & $121(18.3)$ & $301(33.8)$ & \\
\hline Only gets breathless after exercising heavily & $55(8.3)$ & $305(34.2)$ & \\
\hline \multirow[t]{2}{*}{ Mean EQ-5D (patient-reported) } & 0.59 & 0.82 & $<0.0001$ \\
\hline & $\mathrm{n}=400$ & $\mathrm{n}=56 \mathrm{I}$ & \\
\hline \multirow[t]{2}{*}{ Number of exacerbations in the last 12 months, mean (SD) } & $1.69(2.37)$ & $0.4 I(0.86)$ & - \\
\hline & $\mathrm{n}=604$ & $\mathrm{n}=869$ & \\
\hline \multirow[t]{2}{*}{ Mean number of maintenance products for COPD ${ }^{d}$} & 2.8 & 2.3 & $<0.0001$ \\
\hline & $n=670$ & $n=901$ & \\
\hline \multirow[t]{2}{*}{ Visits to physician in the last 12 months, mean (SD) } & 6.19 & 3.88 & $<0.0001$ \\
\hline & $\mathrm{n}=665$ & $n=897$ & \\
\hline \multirow[t]{2}{*}{ Hospital admissions, mean (SD) } & 0.48 & 0.08 & $<0.0001$ \\
\hline & $n=64 I$ & $\mathrm{n}=850$ & \\
\hline \multirow[t]{2}{*}{ Emergency department admissions, mean (SD) } & 0.48 & 0.08 & $<0.000$ I \\
\hline & $n=642$ & $n=850$ & \\
\hline \multirow[t]{2}{*}{ ICU admissions, mean (SD) } & 0.07 & 0.01 & $<0.0001$ \\
\hline & $n=642$ & $\mathrm{n}=850$ & \\
\hline \multirow[t]{2}{*}{ Number of nights spent in ICU, mean (SD) } & 0.29 & 0.02 & $<0.0001$ \\
\hline & $n=64 \mid$ & $n=848$ & \\
\hline \multirow[t]{2}{*}{ Number of nights spent in hospital, mean (SD) } & 3.47 & 0.48 & $<0.0001$ \\
\hline & $\mathrm{n}=637$ & $n=850$ & \\
\hline
\end{tabular}

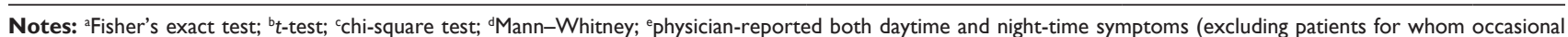

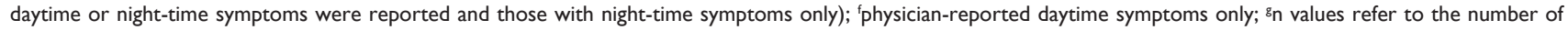
patients for whom a response to the relevant question was available.

Abbreviations: COPD, chronic obstructive pulmonary disease; EQ-5D, EuroQol 5 dimensions measure; FEV , forced respiratory volume over one second; GOLD, Global initiative for chronic Obstructive Disease; ICU, intensive care unit; mMRC, modified Medical Research Council; NTS, night-time symptoms; SD, standard deviation. 
experience COPD-related symptoms when getting up in the morning (as reported by their physician) than those whose physician reported that they did not experience night-time symptoms $(52.4 \%$ versus $19.2 \%$, respectively; $P<0.001)$. They were also more likely to self-report at least some level of sleep disturbance (Jenkins Sleep Questionnaire) in the previous 28 days compared with those without physician-reported night-time symptoms (91.1\% versus $60.5 \%$; $P<0.0001)$. Patients with physician-reported night-time symptoms had significantly poorer health-related quality of life (as assessed using the EQ-5D) compared with those without physicianreported night-time symptoms (mean scores 0.59 and 0.82 , respectively) and significantly higher health care resource utilization $(P<0.0001$, Table 2$)$.

Multivariate regression analysis of the association between night-time symptoms and measures of health status and resource use (Table 3 ) demonstrated a significant association $(P<0.0001)$ between night-time symptoms and a variety of health status-related and resource use-related factors when patients with and without physician-reported night-time symptoms were compared. Thus, the presence of night-time symptoms was associated with higher scores on the Jenkins Sleep Questionnaire and mMRC dyspnea scale (coefficients of 3.493 and 0.446 , respectively), the presence of symptoms when getting up in the morning (coefficient 0.237), a lower EQ-5D state valuation (coefficient -0.101), and increased health care resource utilization, including number of physician visits (coefficient 2.518) and hospital admissions (coefficient 0.187 ).

\section{Impact of COPD on lifestyle factors}

The difference between physician and patient perception of the impact of COPD was statistically significant for the impact on the patients' ability to get up in the morning (mean scores 3.05 and 3.12, respectively, $P=0.018$ ) and for the impact on sleep (mean scores 2.84 and 3.02, respectively, $P<0.0001$, Figure 3 ). The difference in perception of the impact of COPD was of borderline significance for the patient's ability to complete their normal daily activities (mean scores 3.38 and 3.44 , respectively, $P=0.0535$ ). The level of agreement (kappa statistic) across the lifestyle factors evaluated was regarded as fair to moderate.

\section{Discussion}

In this cohort of more than 2,800 patients with COPD, the majority reported some degree of sleep disturbance in the previous 28 days, including trouble falling asleep, waking up during the night, trouble staying asleep, and waking up feeling worn out after a usual amount of sleep.

Physicians reported that their patients experienced a variety of COPD-related symptoms both during the night and on waking in the morning, and that the majority of patients (67.3\%) experienced night-time symptoms. When the patient cohort was stratified for the presence of night-time symptoms, those with nocturnal symptoms also experienced more daytime breathlessness and more frequent exacerbations, and used more maintenance products than those without night-time symptoms. Moreover, patients with night-time symptoms appeared to be more likely to experience difficulty in getting up in the morning, disturbed sleep, and poorer quality of life.

There appeared to be a good level of concordance between the frequency of physician-reported and patient-reported night-time symptoms. However, physicians appeared to significantly underestimate the impact of COPD on the ability of patients to get up in the morning and on sleep. A survey of more than 800 patients with COPD in Europe and the US revealed a range of activities that were impacted by the

Table 3 Association of night-time symptoms and health and resource use-related factors

\begin{tabular}{|c|c|c|c|c|}
\hline Factor & Observations & Coefficient & $95 \% \mathrm{Cl}$ & $P$-value \\
\hline Jenkins Sleep Questionnaire & 829 & 3.493 & $2.778-4.207$ & $<0.0001$ \\
\hline Symptoms when getting up in the morning & 880 & 0.237 & $0.165-0.309$ & $<0.0001$ \\
\hline EQ-5D state valuation & 842 & -0.101 & -0.138 to -0.064 & $<0.0001$ \\
\hline mMRC dyspnea scale & 871 & 0.446 & $0.582-0.310$ & $<0.0001$ \\
\hline Number of physician visits & 876 & 2.518 & $1.825-3.211$ & $<0.0001$ \\
\hline Number of hospital admissions & 834 & 0.187 & $0.114-0.261$ & $<0.0001$ \\
\hline Number of emergency department admissions & 834 & 0.216 & $0.151-0.281$ & $<0.0001$ \\
\hline Number of ICU admissions & 834 & 0.034 & $0.009-0.059$ & 0.009 \\
\hline Number of nights in ICU & 834 & 0.130 & $0.037-0.222$ & 0.006 \\
\hline Number of nights in hospital & 832 & 1.277 & $0.640-1.913$ & $<0.0001$ \\
\hline Number of maintenance products currently prescribed & 880 & 0.189 & $0.080-0.298$ & $<0.001$ \\
\hline
\end{tabular}

Abbreviations: $\mathrm{Cl}$, confidence interval; EQ-5D, EuroQol 5 dimensions measure; ICU, intensive care unit; mMRC, modified Medical Research Council. 


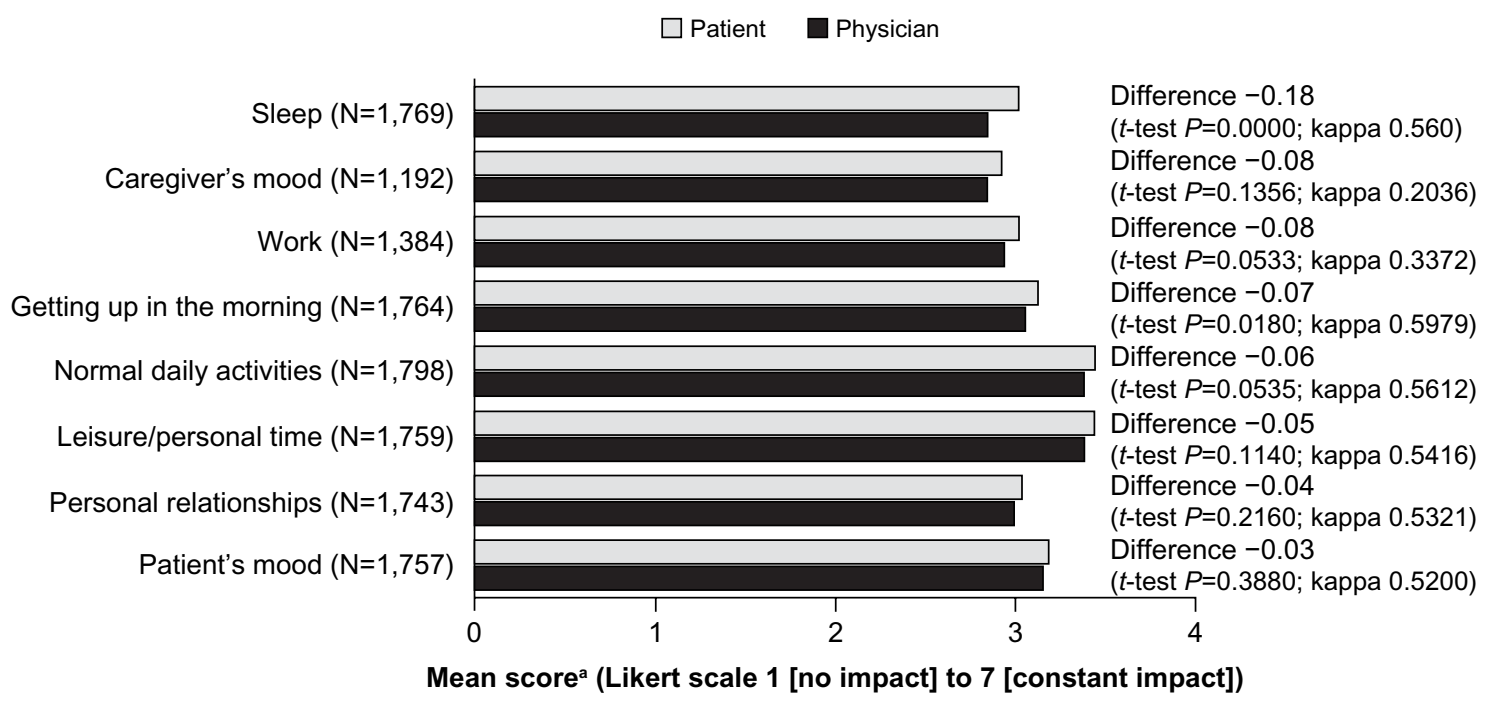

Figure 3 Impact of COPD on lifestyle factors, as assessed by patients and their physicians (the analysis set was the cohort for whom both physician-reported and patientreported data were available).

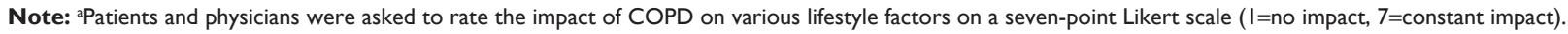
Abbreviation: COPD, chronic obstructive pulmonary disease.

disease in the mornings, including the ability to walk up and down stairs, washing and personal hygiene, and getting dressed. ${ }^{17}$ A more directed approach to relieving or improving sleep quality and quantity by addressing night-time symptoms may be of particular benefit to patients in reducing how bothersome the disease is perceived to be. A number of recent studies have highlighted the high symptom burden and significant impact on global quality of life for patients with COPD, a burden which has been estimated to be comparable with that of patients with cancer. ${ }^{18,19}$

The strengths of the study reported here include the large cohort of patients $(>2,800)$ and the collection of data from both the physician's and patient's perspective. A number of the analyses presented here required comparison of both physician-reported and patient-reported data and so were conducted in the subgroup of patients for whom such data were available $(n=1,777)$. A comparison of the baseline demographic and disease characteristics in this subgroup with the cohort of patients having only physician-reported data revealed that patients for whom physician-only data was available tended to be slightly older, had a slightly lower mean $\mathrm{FEV}_{1}$, and were slightly more breathless (all as reported by their physician) than the cohort of patients with both physician-reported and patient-reported data. Although these differences reached statistical significance, the absolute differences were small and, in the opinion of the authors, are unlikely to bias the conclusions presented here. Multivariate techniques were also employed to take into consideration a number of confounders (Table 3). The study is limited by the collection of data only from patients presenting for care (primary or specialist). As such, this cohort of patients may represent those more bothered by their symptoms at the time of the study. The cross-sectional nature of the data also limits the conclusions that can be drawn from the data presented here to an observed association rather than a causal relationship, particularly given that a number of analyses were conducted in subgroups of patients where both physician-reported and patient-reported data were available. Finally, the data must be viewed with caution given that it was not possible to adjust the data in order to account fully for the contribution of disease severity to the observations reported here.

The results of this retrospective analysis of a large cohort of patients with COPD have demonstrated a high prevalence of sleep disturbance and a high frequency of nocturnal COPD-related symptoms. The prevalence of nighttime symptoms appears to increase with increasing disease severity. However, our study suggests that even patients who meet the criteria for GOLD categories A and B report a considerable amount of night-time symptoms. Patients report a considerable impact of COPD on their ability to get up in the morning and their sleep. These results indicate a need to increase the awareness of the impact of COPD symptoms on sleep and to specifically address the burden of night-time symptoms and early morning symptoms in patients with COPD. Identifying patients with night-time and early morning symptoms would allow physicians to tailor treatment to address this unmet need with the aim of improving patient quality of life and health status. 


\section{Acknowledgment}

We thank Caglar Karakurum (formerly of Almirall S.A.) for his contributions to data interpretation and initial drafting of this manuscript.

\section{Disclosure}

This study was sponsored by Almirall S.A., Barcelona, Spain. Medical writing support was provided by Tracey Lonergan of Complete Medical Communications, and was funded by Almirall S.A.

\section{References}

1. Global Initiative for Chronic Obstructive Lung Disease. Global strategy for the diagnosis, management, and prevention of chronic obstructive pulmonary disease [updated 2013]. Available from: http://www. goldcopd.org/guidelines-global-strategy-for-diagnosis-management. html. Accessed March 5, 2013.

2. Valipour A, Lavie P, Lothaller H, Mikulic I, Burghuber OC. Sleep profile and symptoms of sleep disorders in patients with stable mild to moderate chronic obstructive pulmonary disease. Sleep Med. 2011;12(4): 367-372.

3. Budhiraja R, Parthasarathy S, Budhiraja P, Habib MP, Wendel C, Quan SF. Insomnia in patients with COPD. Sleep. 2012;35(3):369-375.

4. Agusti A, Hedner J, Marin JM, Barbé F, Cazzola M, Rennard S. Night-time symptoms: a forgotten dimension of COPD. Eur Respir Rev. 2011;20(121):183-194.

5. Nunes DM, Mota RM, de Pontes Neto OL, Pereira ED, de Bruin V, de Bruin PF. Impaired sleep reduces quality of life in chronic obstructive pulmonary disease. Lung. 2009;187(3):159-163.

6. Scharf SM, Maimon N, Simon-Tuval T, Bernhard-Scharf BJ, Reuveni H, Tarasiuk A. Sleep quality predicts quality of life in chronic obstructive pulmonary disease. Int J Chron Obstruct Pulmon Dis. 2011;6:1-12.
7. Banks S, Dinges DF. Behavioral and physiological consequences of sleep restriction. J Clin Sleep Med. 2007;3(5):519-528.

8. Chandola T, Ferrie JE, Perski A, Akbaraly T, Marmot MG. The effect of short sleep duration on coronary heart disease risk is greatest among those with sleep disturbance: a prospective study from the Whitehall II cohort. Sleep. 2010;33(6):739-744.

9. Dettoni JL, Consolim-Colombo FM, Drager LF, et al. Cardiovascular effects of partial sleep deprivation in healthy volunteers. J Appl Physiol. 2012;113(2):232-236.

10. Anderson P, Benford M, Harris N, Karavali M, Piercy J. Real-world physician and patient behaviour across countries: Disease-Specific Programmes - a means to understand. Curr Med Res Opin. 2008;24(11): 3063-3072.

11. European Pharmaceutical Market Research Association. Code of Conduct for International Healthcare Market Research. Available from: http://www.ephmra.org/. Accessed March 26, 2013.

12. Jenkins CD, Stanton BA, Niemcryk SJ, Rose RM. A scale for the estimation of sleep problems in clinical research. $J$ Clin Epidemiol. 1998;41(4):313-321.

13. Rabin R, de Charro F. EQ-5D: a measure of health status from the EuroQol Group. Ann Med. 2001;33(5):337-343.

14. Landis JR, Koch GG. The measurement of observer agreement for categorical data. Biometrics. 1977;33(1):159-174.

15. Emsley R, Lunt M, Pickles A, Dunn G. Implementing double robust estimators of causal effects. Stata J. 2008;8(3):334-353.

16. Lunceford JK, Davidian M. Stratification and weighting via the propensity score in estimation of causal treatment effects: a comparative study. Stat Med. 2004;23(19):2937-2960.

17. Partridge MR, Karlsson N, Small IR. Patient insight into the impact of chronic obstructive pulmonary disease in the morning: an internet survey. Curr Med Res Opin. 2009;25(8):2043-2048.

18. Bausewein C, Booth S, Gysels M, Kuhnbach R, Haberland B, Higginson IJ. Understanding breathlessness: cross-sectional comparison of symptom burden and palliative care needs in chronic obstructive pulmonary disease and cancer. J Palliat Med. 2010;13(9):1109-1118.

19. Joshi M, Joshi A, Bartter T. Symptom burden in chronic obstructive pulmonary disease and cancer. Curr Opin Pulm Med. 2012;18(2): 97-103.
International Journal of COPD

\section{Publish your work in this journal}

The International Journal of COPD is an international, peer-reviewed journal of therapeutics and pharmacology focusing on concise rapid reporting of clinical studies and reviews in COPD. Special focus is given to the pathophysiological processes underlying the disease, intervention programs, patient focused education, and self management protocols.

\section{Dovepress}

This journal is indexed on PubMed Central, MedLine and CAS. The manuscript management system is completely online and includes a very quick and fair peer-review system, which is all easy to use. Visit http://www.dovepress.com/testimonials.php to read real quotes from published authors. 